\title{
Editorial
}

\section{Energías renovables}

\author{
M. Casamitjana
}

MsC Física ambiental.

Colombia se encuentra en una ubicación privilegiada a nivel geográfico para poder generar energías renovables al ubicarse en la zona ecuatorial del planeta y adicionalmente cuenta con una gran variedad de climas y ecosistemas, lo que deriva en una gran aptitud para desarrollar energías limpias renovables.

En referencia a la energía renovable, actualmente Colombia tiene un porcentaje muy elevado de energía generada mediante centrales hidroeléctricas, pero esta energía se está viendo afectada por fenómenos climáticos como son largos periodos de sequía tal cual sucedió con el fenómeno del niño que sufrió Colombia el año 2016. Otro factor a considerar es el impacto ambiental negativo que ocasiona represar los ríos al controlar sus caudales a menudo por debajo del caudal ecológico.

Las otras energías renovables, las no convencionales, son la energía eólica, solar, geotérmica, mareomotriz y la obtenida a partir de biomasa. Estas energías no tienen una afectación negativa con el cambio climático y en Colombia también tienen un alto potencial.

Estudios recientes (Edsand, 2017) (Valencia et al., 2014), afirman que si Colombia utilizara la mitad su potencial en energía eólica, sería capaz de suplir la demanda nacional eléctrica y que actualmente solo se está aprovechando un $0,4 \%$ de su potencial en este tipo de energía renovable.

La producción de energías renovables en el medio colombiano precisa de inversión en investigación para alcanzar la optimización de dichas energías y de una política que favorezca dicho aprovechamiento (Jiménez et al., 2016) 
(Duque et al., 2016), sobretodo en el caso de la energía solar la cual carece de una política colombiana concreta que favorezca la difusión y el desarrollo de dicha energía en zonas alejadas.

A inicios de 2017 la Unión Europea anunció que destinará cerca de $\$ 12.400$ millones para fomentar proyectos de energía renovable no-convencional en Colombia (El espectador, 2017). La producción de energías alternativas en Colombia, con menos emisiones de gases de efecto invernadero tiene un gran potencial de disminuir el impacto sobre cambio climático. Colombia debe aceptar el reto y llevar a cabo proyectos innovadores que desencadenen un nuevo modelo de crecimiento orientado a mejorar la calidad de vida de las personas.

Painuly (2001) definió que a modo general la dificultad de aplicabilidad y difusión de las energías renovables a nivel de país se deben a diferentes factores como las barreras técnicas, las de costo-efectividad, las limitaciones de mercado (precio inconsistente debido a las infraestructuras existentes), barreras referentes a la normativa y política nacional y por último limitaciones sociales.

En el contexto colombiano Rosso-Cero \& Kafarov (2015) realizaron un estudio del caso de la difusión de las energías renovables y encontraron que adicional a las barreras políticas existen reticencias sociales, de aceptación de mercado y aceptación de la comunidad que afectan el desarrollo de las energías renovables en el mercado colombiano, concluyendo que las barreras relacionadas con la aceptación de mercado son las más limitantes.

Olaya et al. (2016) y otros autores como Márquez et al. (2014) afirman que la limitación principal del freno del desarrollo de las energías renovables en Colombia ha sido precisamente el elevado desarrollo de la energía hidroeléctrica que ha eclipsado las otras energías renovables.

Dichas limitaciones en Colombia, sean las que sean, precisan que se minimicen mediante la optimización de los recursos destinados a investigación en energías renovables así como que se realice divulgación científica de sus resultados. Al revertir las limitaciones existentes se espera ver como el porcentaje de energía limpia producida en Colombia se incremente año tras año.

En este volumen 22 de la revista Cintex, se presentan resultados de investigación aplicada a las energías renovables como son la energía solar y la 
energía hídrica, así como un artículo que analiza la eficiencia de operación de almacenadores de energía en micro-redes.

\section{Referencias}

E. Duque, J. Patiño, and L. Velez, "Implementation of the ACMoooz methodology in small hydropower plants in Colombia under the Clean Development Mechanism," International Journal of Renewable Energy Research, vol. 6, no. 1, pp. 21-33, 2016.

El espectador. 2017. http://www.elespectador.com/noticias/economia/destinan12000-millones-energias-renovables-colombia-articulo-673077

H.E. Edsand. 2017. Identifying barriers to wind energy diffusion in Colombia: A function analysis of the technological innovation system and the wider context. Technology in Society 49 (2017) 1-15. Elsevier.

A. Marquez, J. Patino, and J. Espinosa, "Min-Max Economic Model Predictive Control," in Decision and Control (CDC2014), 53rd IEEE Conference on, Los Angeles, CA, 2014, pp. 1-5.

A. M. Rosso-Cero \& V. Kafarov. 2015. Barriers to social acceptance of renewable energy systems in Colombia. Current Opinion in Chemical Engineering 2015, 10:103110. Elsevier

M. Jiménez, C. J. Franco, I. Dyner. 2016. Diffusion of renewable energy technologies: The need for policy in Colombia. Energy 111 (2016) 818-829. Elsevier.

Y. Olaya, S. Arango-Aramburo, E. R. Larsen 2016. How capacity mechanisms drive technology choice in power generation: The case of Colombia. Renewable and Sustainable Energy Reviews 56(2016)563-571

J.P. Painuly. 2001. Barriers to renewable energy penetration; a framework for analysis. Renewable Energy 24 (2001) 73-89

F. Valencia, J. D. López, J. A. Patiño, and J. J. Espinosa, "Bargaining Game Based Distributed MPC," in Distributed Model Predictive Control Made Easy, vol. 69, J. M. Maestre and R. R. Negenborn, Eds. Springer Netherlands, 2014, pp. 41-56. 